\section{Stamp out fake peer review}

In the wake of large-scale retraction scandals, we urge scientific publishers to be more proactive in stamping out fake peer-reviewing practices. They should work with editors, authors and research institutes to implement an effective system of precautions and penalties.

Fraudulent peer review can arise when editors rely on authors' recommended reviewers. These names are often genuine but have a false e-mail address that enables the authors to write a favourable review of their own paper.

Springer Nature, also the publisher of Nature, this year retracted 107 papers from one of its journals on the basis of fake peer review (see T. Stigbrand Tumor Biol. http://doi.org/b7gg; 2017). Two years ago, it retracted 64 articles in 10 of its journals on similar grounds (see Nature http://doi.org/b7gh; 2015).

In our view, retracting such papers is not enough. Editors need to double-check the authenticity of potential reviewers and insist that authors provide academic identities for their suggested reviewers, including institutional e-mail addresses, ORCID identifiers and Scopus Author IDs.

Journals should confidentially share each other's databases of falsified reviewers' details and of offending authors. Publishers could then reject new submissions from those authors for a set period. National academic committees and research institutes might consider revoking research funding for such authors and demoting them. Jian Gao, Tao Zhou University of Electronic Science and Technology of China, Chengdu, China. gaojian08@std.uestc.edu.cn

\section{Value coordinating roles in research}

Academic-coordination roles can be even harder to sell on a $\mathrm{CV}$ than teaching responsibilities (see Nature http://doi.org/b7gn; 2017). These include activities such as mentoring students; organizing research projects, meetings, workshops and talks; managing data; and running a lab group's websites and social media - all of which steal crucial time away from research.

Paradoxically, it therefore pays the coordinator (typically a female or early-career scientist, who may already be at a disadvantage compared with their peers) to put their research career first and to spend as little time as possible on 'unprofitable' coordinating tasks. This renders a disservice to students, outreach and, ultimately, research itself.

The problem lies in academia undervaluing such skills and non-research-related responsibilities. In our view, these contributions should be recognized on a par with publications and winning grants, and as an advantage — not a disadvantage - to a research career.

Eleanor M. Slade University of Oxford, UK.

Terhi Riutta Imperial College

London, UK.

eleanor.slade@zoo.ox.ac.uk

\section{Lure young surgeons on to research tracks}

To help alleviate the shortage of surgeon-scientists in the United States, MD-PhD training programmes funded by the National Institutes of Health (NIH) need reforming to encourage more clinicianscientist trainees to consider this career path (see Nature 544, 393-394; 2017).

Many surgical-residency programmes offer research tracks. I suggest that these research opportunities be introduced after residency, during the training for sub-speciality fellowships as is more commonly done in subfields of internal medicine. That would allow surgeonscientists to collect preliminary data to help them win research grants once they are junior faculty members.

Although the NIH provides funding for early-career clinicianscientists, most research institutes require a $75 \%$ time commitment - an unrealistic demand for many junior surgical faculty members. The National Institute of Arthritis and Musculoskeletal and Skin Diseases and the National Institute of Neurological Disorders and Stroke recognize this and require their orthopaedic surgeons and neurosurgeons, respectively, to spend only half of their time on research. Other institutes should consider following their example to spur research work in other surgical disciplines.

Hospital administrators and department chairs of academic medical centres can also help by providing surgeon-scientists with protected research time.

Daniel S. Alt Case Western Reserve University, Cleveland, Ohio, USA.

dsa8@case.edu

\section{Stable identifiers for collection specimens}

Members of the Consortium of European Taxonomic Facilities have adopted a consistent citation system for an estimated 20 million biological and geological specimens from European collections. We encourage researchers, publishers and other institutions to engage with this initiative by citing the full specimen identifier in their publications and data sets.

These specimens provide reference material for research on evolution, genetics, mineralogy, ecology and taxonomy - hence the need for a reliable identification system for citation (see A. Güntsch et al. Database 1, bax003; 2017).

Our system assigns a unique and permanent Uniform Resource Identifier (URI) to each specimen. It follows Linked Open Data principles (see www.w3.org/tr/ld-bp) by including a redirection facility to human- and machinereadable representations of the specimen. It also gives credit to the collectors and custodians. For example, the alpine plant specimen Leptinella scariosa Cass., held by the Royal Botanic Garden in Edinburgh, UK, and collected in Chile by Charles Darwin in 1834, is referred to by the URI http://data.rbge.org.uk/ herb/E00070244.

Quentin Groom Botanic Garden Meise, Belgium. Roger Hyam Royal Botanic Garden Edinburgh, UK.

Anton Güntsch Botanic Garden and Botanical Museum, Berlin, Germany. quentin.groom@plantentuinmeise.be

\section{Rejuvenation study stirs old memories}

The media reaction to the revitalization of aged mice by a human protein (see Nature http://doi.org/b7gd; 2017, and J. M. Castellano et al. Nature 544, 488-492; 2017) echoes the enthusiasm that greeted rejuvenation techniques proposed almost a century ago by the Austrian endocrinology pioneer Eugen Steinach.

Following his experiments on rats and guinea pigs, Steinach's surgical interventions in humans included unilateral vasectomy and vasoligation (E. Steinach Rejuvenation through the Experimental Revitalization of the Aging Puberty Gland; Springer, 1920). The procedure was eagerly taken up in 1923 by neurologist Sigmund Freud and in 1934 by the Irish poet W. B. Yeats. Although the operation had its critics (see, for example, M. Fishbein The Medical Follies; Boni \& Liveright, 1925), Steinach was nominated at least 11 times for the Nobel Prize in Physiology or Medicine between 1921 and 1938. He never received the prize. Matthis Krischel, Nils Hansson Heinrich Heine University Düsseldorf, Germany. nils.hansson@hhu.de 